\title{
CANDIDA ALBICANS: GENOTYPING METHODS AND CLADE RELATED PHENOTYPIC CHARACTERISTICS
}

\author{
Juliana P. Lyon ${ }^{1,5}$ *, Karen C.M. Moraes ${ }^{2,5}$, Leonardo M. Moreira ${ }^{1}$, Flávio Aimbire ${ }^{3}$, Maria Aparecida de Resende ${ }^{4}$ \\ ${ }^{1}$ Universidade Federal de São João Del Rei, São João Del-Rei, MG, Brasil; ${ }^{2}$ Universidade Federal de Ouro Preto, Ouro Preto, \\ MG, Brasil; ${ }^{3}$ Universidade Camilo Castelo Branco, Núcleo de Engenharia Biomédica, São José dos Campos, SP, Brasil; \\ ${ }^{4}$ Instituto de Ciências Biológicas da Universidade Federal de Minas Gerais, Belo Horizonte, MG, Brasil; ${ }^{5}$ Universidade do \\ Vale do Paraíba, São José dos Campos, SP, Brasil.
}

Submitted: November 11, 2009; Returned to authors for corrections: February 26, 2010; Approved: April $26,2010$.

\begin{abstract}
Several molecular methods, such as Southern blotting hybridization, Multilocus Sequence Typing, and DNA microsatellite analysis, have been employed to genotype Candida albicans. The genotype analysis allows to group strains in clades, that is, a group composed of one ancestor and its descendants. These genotype studies demonstrate that clades distribution is influenced by geographic area as well as that antifungal resistance is associated with particular clades. These findings suggested that C. albicans reproduces mainly in a clonal manner, with certain degree of DNA microevolution. Additionally, virulence factors and site of isolation have also been associated with clade specificity. The present article is a brief review about the methods used for Candida genotyping and the correlated clade systems established. Special emphasis is given to $\mathrm{Ca} 3$ hybridization, MLST, and Microsatellites. The present work is also focused on the phenotypic and physiological traits associated with Candida clades.
\end{abstract}

Key words: Candida albicans; clonal reproduction; microevolution; genotyping systems; phenotypic characteristics.

\section{INTRODUCTION}

Candida yeasts components of normal human microbiota, being present in a large percentage of healthy individuals (36). However, in a diverse range of debilitated and immunocompromised hosts, Candida infections may cause relevant number of morbidity and mortality cases which constitute a serious public health problem $(21,23)$. Conditions such as immunodeficiency, endocrine disorders, radiotherapy or malignant diseases can be identified as predisposing factors to candidiasis. Several species have been reported to be responsible for infection such as C. krusei, C. tropicalis, $C$. glabrata, and C. guilliermondii; however, C. albicans has been considered the major etiological agent between them $(11,15$, 22, 31).

Several methodologies have been used for typing $C$. albicans, such as electrophoretic karyotyping (14, 16, 43, 52) Restriction Fragment Length Polymorphism (RFLP) (12), Random Amplified Polymorphic DNA (RAPD) (5, 24, 36), Multilocus Enzyme Electrophoresis (MLEE) (2, 6, 45), Microsatellites (7, 28), Multilocus Sequence Typing (MLST) $(9,32,58)$, and DNA fingerprinting with $\mathrm{Ca} 3$ probe $(4,40)$. The present review focus on DNA probe Ca3, MLST, and Microsatellites. The experiments developed with these techniques can be reproduced (38), results obtained from different laboratories can be compared with a high degree of 
confidence (49). The techniques mentioned are employed for the classification of Candida strains into groups formed by a single ancestor and its descendants, which are also called clades.

C. albicans is a diploid specie with substantial heterozygosity (37), but predominant reproduces in a clonal mode $(27,30,42)$. The genomic microvariation that has been documented for multiple $C$. albicans isolates from single patients $(8,27,39,47)$ occurs due to recombination (57), mitotic crossing over (37), and ploidy changes based on chromosome morphological alterations (48, 59).Odds et al., (33) suggested that the population of cells colonizing or infecting a particular site in a patient comprises a mixture of cells with nearly identical genomes.

The identification of microvariation between strains helps to understand the dynamics of the genetic microevolution in Candida population, and its connection with the appearance of drug-resistant strains. Moreover, $C$. albicans and related species undergo spontaneous high-frequency switching among a limited number of general phenotypes that reflect an immediate environmental influence such as sensitivity to antifungal agent, assimilation of carbohydrates, and even morphology alterations of the colony (54). These immediate changes in Candida species reflect alterations in the pattern of gene expression, required for the adjustment of their metabolic reactions needed for the maintenance of their cellular homeostasis. Thus, modern methodological techniques have been used in order to discriminate the strains in a systemic fungal infection, which is crucial for early and specific initiation of antifungal therapy.

Considerable conserved extensions of DNA are present between $C$. albicans strains, because in these organisms, microevolution works as a result of local evolutive mechanisms. The individuality of each strain can be detected based on specific tandem repeats sequences randomly distributed over the genome, which are highly polymorphic between the individuals. DNA fingerprinting techniques provide quantitative data that reflect the precise genetic distance between strains. In this way, the strains analyzed can be classified as identical, related or non-related.

In clinical investigation, DNA fingerprinting methods help on strain discrimination and on the answering of epidemiological questions such as: (i) understanding the dynamics of an infectious organism in a human population, (ii) comprehending the relationship between commensalism and infection, (iii) identifying the origin of an infection, and (iv) monitoring the emergence of drug-resistant strains (54). If such questions are solved, molecular genotyping can impact on the management of Candida infections.

A detailed view on Candida genotyping classification is discussed in the present review, and a final correlation between the phenotype characteristics of the strains and their association with clade groups is present.

\section{DNA fingerprinting with C3a probe}

One of the most common methodologies employed in genotyping through DNA fingerprinting is Restriction Length Polymorphism (RFLP) followed by the Southern blot technique and specific probe hybridization. The most successful hybridization probes for fungi are fragments containing repetitive genomic sequences, such as Ca3 (54). $\mathrm{Ca} 3$ is a moderately repetitive $11-\mathrm{kb}$ C. albicans gene fragment which has been used as an effective DNA fingerprinting probe in several epidemiological studies.

When probed with the entire $\mathrm{Ca} 3$ fragment, EcoRIdigested DNA of $C$. albicans strain 3153A exhibit patterns composed of 10 to 20 bands of relatively high intensity and 4 to 6 bands of low intensity $(1,54)$. While the entire pattern of hybridization has been used to assess the relatedness of isolates, the subset of hypervariable bands have been used to monitor the microevolution of strains at sites of infection or carriage $(51,54)$. The software Dendron is employed to generate dendrograms, through computational analysis of the patterns obtained by Southern blotting hybridization. The software combines the results of image processing, gel image analysis, computation of similarity coefficients, genesis of dendrograms, and is also able to storage the data for future retrospective analyses (54). Because Dendron retains the 
digitized Ca3 Southern blot hybridization pattern of every $C$. albicans strain analysed, and retrospectively compares all newly analysed strains with all previously analysed strains, a data bases for epidemiological studies have been developed. These data have been considered in the analysis of geographical distribution, transmission, and strain specialization (54).

The fingerprinting of $C$. albicans employing Southern blot hybridization with the midrepeat sequence $\mathrm{Ca} 3$ has proven to be reproducible and highly amenable to computer-assisted analysis (38). Pujol et al (38) used $\mathrm{Ca} 3$ fingerprinting to analyse the genetic relatedness of a small collection of $C$. albicans isolates recovered in the United States of America, and clustered the samples into three groups named I, II and III. Subsequently, Blignaut et al (3) analysed the genetic relatedness of C. albicans collected from the oral cavity of HIV positive and healthy South African individuals. This work revealed a South African specific group, named SA. This $C$. albicans group is present in $53 \%$ of isolated collected from black South Africans and it is also present in $33 \%$ of the isolated collected from white South Africans. These results clear demonstrated an interesting pattern of racial differences in host colonization. Furthermore, Pujol et al (40) identified the presence of a European-specific group (group E), and this group represented $26 \%$ of European $C$. albicans isolates. It is also interesting to note that when samples obtained in USA Southwest and South America were analysed from genetic relatedness, no isolates clustered into group II (40). The importance of this series of articles was the establishment of clades with specific characteristics that can be compared with future epidemiological assays.

Soll and Pujol (55) analyzed the geographic distribution of Candida isolates according to the clade system developed in the previous works. According to these authors, isolates belonging to clade I were consisted in the major group in North America, and were less representative in South Africa and Europe. Isolates belonging to calde II represented a relatively small population in North America, Europe and South Africa and this population was absent in South America and
Southwest US. Clade III isolates corresponded to 23 and $24 \%$ of South America and North America isolates respectively, but ranged from 6 to $7 \%$ among samples obtained in South Africa and Europe. Clade III isolates were more prevalent in Southwest USA (51\%). Moreover, the authors analysed the regional distribution of the isolates belonging to group SA, which is strongly represented in South African strains but was poorly represented among the $C$. albicans strains from other regions studied. The distribution of Clade $\mathrm{E}$ isolates was predominant in Europe and appeared in a lower percentage rates in other geographic sites. Based on the above observations, and in the presence or absence of the intervenient retrotransposon IS1 sequence in the $25 \mathrm{~S}$ rRNA gene, Soll and Pujol (2003) also speculated an evolutionary relationship between $C$. albicans strains. According to their analysis, a phylogenetic tree was suggested and in which the SA group diverged from the other strains in the initial of the evolutionary process; the other strains looked to be more correlated between themselves. That is, a common ancestor derived the SA clade and another branch. Clades I, II, III and E are derived from this earlier branch.

Another interesting work was developed by Edelmann et al (18) using DNA fingerprinting with $\mathrm{Ca} 3$ probe. They verified the genetic relatedness of $C$. albicans cultures obtained from human and animal sources. The phylogenetic analysis did not reveal the existence of species-specific lineages, which suggested that animals could be possible resources for Candida infection. However, although no species specificity has been demonstrated, different $C$. albicans clades may differ in the frequency in which they colonize various species.

DNA fingerprinting with the complex probe $\mathrm{Ca} 3$ thus represents an interesting method for Candida genotyping which has been contributing to the understanding of the differences between strains traits.

\section{Multilocus Sequence Typing}

Multilocus sequence typing is a highly discriminatory and practical approach to distinguishing strains within microorganism species (29). Molecular typing data obtained 
through MLST can be shared via internet (http://www.mlst.net), allowing global epidemiologic analysis. The technique is used for typing multiple loci in the genomic DNA and became the method of choice for Candida typing (9, 10). MLST involves DNA amplification by Polymerase Chain Reaction (PCR) followed by DNA sequence. It measures the DNA sequence variation in a set of housekeeping genes and characterizes strains by their unique allelic profiles. The characterization is based on the analysis of nucleotide polymorphisms of the sequences of approximately 450- to 500bp internal fragments (loci) of housekeeping genes. For each housekeeping locus, different sequences present within the species are considered as distinct alleles. The large number of alleles at each housekeeping gene analyzed permits the construction of different allelic profiles. These data can be used to construct a dendogram using the matrix of pairwise differences between their allelic profiles that can be assumed to be derived from a common ancestor.

Bougnoux et al (9) and Tavanti et al (58) were the first researches that described a set of gene fragments for MLST of C. albicans. Based on these previous efforts, Bougnoux et al (2003) developed an optimized protocol for MLST of $C$. albicans. The authors proposed the following set of gene fragments as international standard protocol for MSLT in the fungi: AAT1a, ACC1, ADPI, MPIb, SYA1, VPS13, and ZWF1b. This set yielded unique diploid sequence types for each isolate tested.

According to Chowdahry et al (13), MLST can be applied to define genetic relatedness of sequential $C$. albicans isolates, achieving equal or even better results than when the analysis is performed by Ca3 Southern hybridization. Similarly, Robles et al (44) demonstrated that MLST is at least comparable with random amplified polymorphic DNA (RAPD), multilocus enzyme electrophoresis (MLEE) and Southern blotting in discriminating $C$. albicans strains.

When data obtained by MLST for C. albicans were analysed by unweighted-pair group method with arithmetic mean (UPGMA), the major clades obtained correlate extremely well with clades defined by DNA fingerprinting by $\mathrm{Ca} 3$ hybridization, except for clade E (34). Based on the results, MLST possesses four well defined clades, designated 1 to 4 . It is important to mention that an arbitrary $p$ distance cutoff was employed to delineation of $C$. albicans clades. A minority of isolates can shift to different clades as data set grows. However, the largest clade groups are stable (34).

Tavanti et al (56) developed an interesting study analyzing a collection of $416 C$. albicans isolates that clustered into 11 groups by MLST, named from 1 to 11 . Fifty percent of the isolates belonging to group 5 were resistant to Fluconazole and Itraconazole and isolates that demonstrated resistance to flucytosine were concentrated into groups 1, 5 and 6. However, the number of isolates was too low to allow definitive conclusions.

The correspondence between the clade systems developed by MLST and $\mathrm{Ca} 3$ hybridization is remarkable, because epidemiological studies performed with both methodologies can be compared. Regarding the anatomical sites, the proportion of isolates from blood and other sterile sites that belonged to clade I was lower than in the other major clades. Considering clade I isolates, Four out of five isolates belonged to cluster 1 when eBURST algorithm analysis was performed. Similarly, clade II isolates were related to cluster 2, clade SA isolates corresponded to clade 3 , and clade $\mathrm{E}$ isolates to clade 4. Clade III isolates, as determined by $\mathrm{Ca} 3$ hybridization, corresponded to clusters 9 or 10 when analyzed by eBurst algorithm. In a comparable study, Odds et al (32) evaluated 1391 isolates and demonstrated that $97 \%$ of them could be grouped in one of the 17 groups or clades based on their MLST profile. Groups 1 to 4 comprised the majority of the isolates and these groups corresponded to clades I, II, III and SA respectively, as determined by $\mathrm{Ca} 3$ hybridization. Similarly, Clade 11 corresponded to clade E. This study also established that the proportions of $\mathrm{A}, \mathrm{B}$, and $\mathrm{C}$ genotypes, defined by the presence or absence of an intron in the ribosomal DNA region, differed significantly among clades. In this work, $93 \%$ of strains in clades 1 and 2 were type A. Furthermore, North American isolates were predominantly assigned as clades 1 and 3 and $40 \%$ of African isolates were grouped into clade 4 . 
The studies mentioned above demonstrated that results obtained by MLST can be compared with those obtained by Ca3 hybridization, although the correlation could not be completely demonstrated for all clades. This is an interesting point, due to the possibility of using the results obtained in epidemiological studies. Considering the practicability of the MLST experimental performance and analysis, it is considered as the method of choice for Candida genotyping, which has been largely contributing to the understanding of the evolutionary origins of Candida albicans different strains.

\section{Microsatellites analysis}

Microsatellites are short tandem repeated sequences interspersed randomly through the nuclear and organelles genome, and basically the repeating unit consists of fragments shorter than 10 bases pair (bp). Between the individuals the repeating units number found in the microsatellite varies, which contributes with allele polymorphisms. Besides, the microsatellites are quite unstable and high polymorphic due to mispairing slippage during replication, which lead to their expansion or contraction, and also point mutations inside or outside the repeated region in the genomic structures (53). Interesting they present mendelian codominant inheritance and PCR typing simplicity which make them useful to identify hereditary relationships and for genotyping microorganisms. Microsatellite DNA typing can provide important correlations between genotypes and location of infection, degree of virulence, or drug susceptibility. Such correlations are crucial for proper, large-scale epidemiological analysis (53).

Using microsatellites as molecular markers for microorganisms' genotyping, several polymorphic microsatellite loci were identified in the genome of $C$. albicans (25). Sampaio et al. (46) described a microsatellite locus (CAI) in a non-coding region in the genoma of $C$. albicans and evaluated its applicability to accurately differentiate strains. The discriminatory power of this locus is the highest for any loci tested. Liu et al. (25) developed a study employing polymerase chain reaction-single strand conformation polymorphism (PCR-SSCP) of CAI microsatellite for genotyping of vulvovaginitis $C$. albicans isolates. The molecular results showed a correlation between the groups characterized and their antifungal susceptibility profile. The isolates belonging to the dominant genetic related groups (named as groups A, B, C, and D) were susceptible to amphotericin B, flucytosine, ketoconazole and fluconazole. $C$. albicans genotype A was less resistant to azole antifungals, and C. albicans genotype B was more resistant to itraconazole. Also, Fan et al. (19) reported that the frequency of C. albicans with the dominant genotypes (A to D) from patients with severe vulvovaginal candidiasis was significantly higher than that from patients with mild-to-moderate vulvovaginal candidiasis. This suggested that the CAI genotype distribution of $C$. albicans strains is correlated with the severity of vulvovaginal candidiasis. Typing of independent $C$. albicans strains from sputum and other extragenital clinical samples indicated that few of the strains had the same or similar CAI patterns. These researchers suggested that the distribution of the dominant genotypes in the $C$. albicans strains from the vaginas of asymptomatic women, from extragenital sites, especially the gastrointestinal tracts and oral cavities of women with vulvovaginal candidiasis and from the penises and oral cavities of men will be helpful in elucidating the source of the infection.

\section{Candida clades and phenotypic variations}

The identification of major Candida clades has lead to the investigation of characteristics that could be related to each group. Since clades persist in the same geographic area and recombination is not a frequent event, the evolutionary process inside each clade may occur independently, and this fact may have contributed with the development of specific phenotypes. According to Soll and Pujol (55), every aspect of C. albicans biology and physiology should be reassessed in this basis.

In Pujol et al (41) the authors demonstrated that natural resistance to flucytosine was restricted to group I isolates; $96 \%$ of the isolates studied had increased minimum inhibitory concentrations for flucytosine belonged to group I. Dodgson et al (17) showed that both decreased susceptibility and increased 
resistance correlate in the majority of cases with a point mutation from cytosine to thymine at position 301 of the gene FUR1, which encodes phosphoribosyltransferase. This change results in an amino acid substitution from arginine to cysteine at position 101 in the Furl protein. The authors also showed that the mutation was restricted to clade I strains.

Considering the phenotypic analysis between the strains, Blignaut et al (3), using Ca3 hybridization to fingerprint 38 amphotericin B-resistant in C. albicans isolates, reported that the yeasts clustered in all clades, except clade III. Similarly, Liu et al. (25) associated the dominant groups found by microsatellite analysis with susceptibility profile to antifungal agents. However, the inexistence of studies that correlates the major groups formed by CAI microsatellite genotyping with the clades grouped by $\mathrm{Ca} 3$ hybridization or with MLST limits the analysis of Candida clades and their correlation with the phenotypic characteristics.

Several virulence factors contribute to the pathogenicity of Candida yeasts, including the ability to adhere to epithelial and endothelial cells, to hyphal germination, to extracellular proteinases and phospholipases, and to phenotypic switching (20, 26). Genotyping methods have been employed to investigate the correlation of strains and their virulence, but in many times, the methods employed lacked in accuracy and provided few information (54). Schmid et al (50) performed the clustering of 47 Candida isolates into 22 groups and attempted to correlate these groups with physiological traits in order to explain characteristics that determine colonization or infection. The authors found a great predominance of one group (group 13), which demonstrated the ability of the members of this group in colonizing human individuals. It was also observed that the members of this group were more often resistant to five fungicidal substances tested and that those isolates adhere more strongly to saliva-coated surfaces. The authors suggested that these characteristics may promote the pathogenicity of C. albicans.

The $A L S$ (agglutinin-like sequence) gene family of $C$. albicans encodes eight large cell-surface glycoproteins, some of which act in adhesion process to host cells (35). The protein
Als3p produced on $C$. albicans germ tubes and hyphae demonstrated to have adhesive function. Disruption of $A L S 3$ gene results in cells with reduced adherence to vascular endothelial and buccal epithelial cells, as well as a marked reduction in destruction of epithelial cells in the reconstituted human epithelium in in vitro model of candidiasis (20). Considering this, Zhao et al (60) developed a program with the aim of verifying the occurrence of clade-specific differences regarding ALS3 genes. Clades differed with respect to prevalent $A L S 3$ alleles and its distribution, but were similar for the mean number of tandem repeat copies per $A L S 3$ allele. One allele $(A L S 3(12))$ has 12 tandem repeat copies while the other (ALS3(9)) has 9 copies (35). Other studies related to the ALS gene family and their ability to influence cellular adhesion were also performed by the same research group (61). Using genomic DNA from $C$. albicans isolates from different geographical region, it was PCR-amplified and they demonstrated that prevalent alleles and allelic distributions varied among the clades for ALS5 and ALS6. The authors also observed that ALS6 exhibited less variability than ALS5 and the deletion of both ALS5 alleles was associated particularly with clades III and SA.

Virulence factors of $C$. albicans and resistance to new antifungal agents are aspects that should be reevaluated by correlating the phenotypic characteristics with DNA fingerprinting. Researches have been collaborating to a more wild comprehension about these topics when they use genotyping methods that can be compared with other results in order to form a global profile of virulence related to strain specificity.

\section{CONCLUSION}

The present review presented a brief description of methods employed in $C$. albicans genotyping, with special emphasis to $\mathrm{Ca} 3$ hybridization, MLST and Microsatellites. The arrangement of $C$. albicans yeasts in clades or groups provided important information about this organism regarding the geographic maintenance of strains and in the mode of 
reproduction, which is probably clonal with certain degree of DNA rearrangement that contributes to yeast microevolution. Virulence factors and antifungal resistance can be associated to established clades, but a broad field of investigation must be explored; several physiological traits should be reevaluated on this basis.

\section{ACKNOWLEDGEMENTS}

This work was supported by Fundação de Amparo à Pesquisa do Estado de São Paulo (grant 2007/07162-5) and Fundação Valeparaibana de Ensino.

\section{REFERENCES}

1. Anderson, J.; Srikantha, T.; Morrow, B.; Miyasaki, S.H., White, T.C.; Agabian, N., Schmid, J.; Soll, D.R. (1993). Characterization and partial nucleotide sequence of the DNA fingerprinting probe $\mathrm{Ca} 3$ of Candida albicans, J. Clin. Microbiol. 31(6), 1472-1480. PMID: 8314989.

2. Arnavielhe, S.; De Meeüs, T.; Blancard, A.; Mallié, M.; Renaud, F.; Bastide, J.M. (2000). Multicentric genetic study of Candida albicans isolates from non-neutropenic patients using MLEE typing: population structure and mode of reproduction. Mycoses. 43 (3-4), 109-17. DOI: 10.1046/j.1439-0507.2000.00552.x. PMID: 10907340.

3. Blignaut, E.; Molepo, J.; Pujol, C.; Soll, D.R.; Pfaller, M.A. (2005). Clade-related amphotericin B resistance among South African Candida albicans isolates. Diagn. Microbiol. Infect. Dis. 53(1): 29-31. DOI: 10.1016/j.diagmicrobio.2005.03.013. PMID: 16182076.

4. Blignaut, E.; Pujol, C.; Lockhart, S.; Joly, S.; Soll, D.R. (2002). Ca3 fingerprinting of Candida albicans isolates from human immunodeficiency virus-positive individuals reveals a new clade in South Africa. J. Clin. Microbiol. 40(3), 826-836. DOI: 10.1128/JCM.40.3.826-836.2002. PMID: 11880401.

5. Boldo, X.M.; Villa-Tanaca, L.; Zúñiga, G.; Hernández-Rodríguez, C. (2003). Genetic diversity among clinical isolates of Candida glabrata analyzed by randomly amplified polymorphic DNA and multilocus enzyme electrophoresis analyses. J. Clin. Microbiol. 41(10), 4799-4804. DOI: 10.1128/JCM.41.10.4799-4804.2003. PMID: 14532225.

6. Boriollo, M.F.; Rosa, E.A.; Gonçalves, R.B.; Höfling, J.F. (2006). Parity among interpretation methods of MLEE patterns and disparity among clustering methods in epidemiological typing of Candida albicans. J. Microbiol. Methods. 64, 346-365. DOI: 10.1016/j.mimet.2005.05.012. PMID: 16005996.

7. Botterel, F.; Desterke, C.; Costa, C.; Bretagne, S. (2001). Analysis of microsatellite markers of Candida albicans used for rapid typing. J. Clin.
Microbiol. $\quad 39(11), \quad 4076-4081$. DOI: $\quad$ 10.1128/JCM.39.11.40764081.2001. PMID: 11682532.

8. Bougnoux, M.E.; Diogo, D.; François, N.; Sendid, B.; Veirmeire, S.; Colombel, J.F.; C. Bouchier, C.; Van Kruiningen, H.; d'Enfert, C.; Poulain D. (2006). Multilocus sequence typing reveals intrafamilial transmission and microevolutions of Candida albicans isolates from the human digestive tract. J. Clin. Microbiol. 44, 1810-1820. DOI: 10.1128/JCM.44.5.1810-1820.2006. PMID: 16672411.

9. Bougnoux, M.E.; Morand, S.; d'Enfert, C. (2002). Usefulness of multilocus sequence typing for characterization of clinical isolates of Candida albicans. J. Clin. Microbiol. 40(4), 1290-1297. DOI: 10.1128/JCM.40.4.1290-1297.2002. PMID: 11923347.

10. Bougnoux, M.E. ; Tavanti, A. ; Bouchier, C. ; Gow, N.A. ; Magnier, A. ; Davidson, A.D. ; Maiden, M.C.; D'Enfert, C; Odds, F.C. (2003). Collaborative consensus for optimized multilocus sequence typing of Candida albicans. J. Clin. Microbiol. 41(11), 5265-5266. DOI: 10.1128/JCM.41.11.5265-5266.2003. PMID: 14605179.

11. Budtz-Jorgensen, E.; Mojon, E.; Rentsch, A.; Deslauriers, N. (2000). Effects of an oral healthy program on the occurrence of oral candidosis in a long-term care facility. Community Dent. Oral Epidemiol. 28 (2), 141149. DOI: 10.1034/j.1600-0528.2000.028002141. x. PMID: 10730723.

12. Cardona-Castro, N.; Revankar, S.G.; Ortiz, P.; Cuervo, C., Kirkpatrick, W.R.; McAtee, R.K.; Petterson, T.F. (2002). Proteinase detection, DNA typing and antimycotic susceptibility of Candida isolates from Colombian women with vulvovaginal candidiasis. Rev. Iberoam. Micol. 19 (2), 89-94. PMID: 12828510.

13. Chowdhary, A.; Lee-Yang, W.; Lasker, B.A.; Brandt, M.E.; Warnock, D.W.; Arthington-Skaggs, B.A. (2006). Comparison of multilocus sequence typing and $\mathrm{Ca} 3$ fingerprinting for molecular subtyping epidemiologically-related clinical isolates of Candida albicans. Med. Mycol. 44 (5), 405-417. DOI: 10.1080/13693780600612230. PMID: 16882607.

14. Clemons, K.V.; Feroze, F.; Holmberg, K.; Stevens, D.A. (1997). Comparative analysis of genetic variability among Candida albicans isolates from different geographic locales by three genotypic methods. $J$. Clin. Microbiol. 35(6), 1332-1336. PMID: 9163439.

15. Correia, A.; Sampaio, P.; Almeida, J.; Pais, C. (2004). Study of molecular epidemiology of candidiasis in Portugal by PCR fingerprinting of Candida clinical isolates. J. Clin. Microbiol. 42(12), 5899-5903. DOI: 10.1128/JCM.42.12.5899-5903.2004. PMID: 15583336.

16. Dassanayake, R.S.; Ellepola, A.N.; Samaranayake, Y.H.; Samaranayak, L.P. (2002). Molecular heterogeneity of fluconazole-resistant andsusceptible oral Candida albicans isolates within a single geographic locale. APMIS. 110(4), 315-324. DOI: 10.1034/j.16000463.2002.100406. PMID: 12076267.

17. Dodgson, A.R.; Pujol, C.; Denning, D.W.; Soll, D.R.; Fox, A.J. (2003). Multilocus Sequence Typing of Candida glabrata Reveals Geographically Enriched Clades. J. Clin. Microbiol. 41(12), 5709 - 5717. DOI: 10.1128/JCM.41.12.5709-5717.2003. PMID: 14662965. 
18. Edelmann, A.; Krüger, M.; Schmid, J. (2005). Genetic relationship between human and animal isolates of Candida albicans. J. Clin. Microbiol. 43(12), 6164-6166. DOI: 10.1128/JCM.43.12.61646166.2005. PMID: 16333121.

19. Fan, S.R.; Bai, F.Y.; Liao, Q.P.; Liu, Z.H.; Li, J.; Liu, X.P. (2008). Genotype distribution of Candida albicans strains associated with different conditions of vulvovaginal candidiasis, as revealed by microsatellite typing. Sex. Transm. Infect. 84(2), 103-106. DOI: 10.1136/sti.2007.025700. PMID: 17971371.

20. Gannoum, M. (2000). Potential role of phospholipases in virulence and fungal pathogenesis. Clin. Microbiol. Rev. 13(1), 122-43. PMID: 10627494

21. Gudlaugsson, O.; Gillespie, S.; Lee, K.; Vande, B.J.; Hu, J.; Messer, S.; Herwaldt, L.; Pfaller, M., Diekema, D. (2003). Attributable mortality of nosocomial candidemia, revisited. Clin. Infect. Dis. 37(9),1172-1177. DOI: $10.1086 / 378745$. PMID: 14557960.

22. Haberland-Carrodeguas, C.; Allen, C.M.; Beck, F.M.; Bueschiling, W.J.; Koletar, S.L.; Sundstron, P. (2002). Prevalence of fluconazole-resistant strains of Candida albicans in otherwise healthy outpatients. J. Oral Pathol. Med. 31(2), 99-105. DOI: 10.1034/j.1600-0714.2002.310207.x. PMID: 11896831.

23. Hajjeh, R.A.A.; Sofair, A.N.; Harrinson, L.H.; Lyon, G.M.; ArthingonSkaggs, B.A.; Mirza, S.A.; Phelan, M.; Morgan, J.; Lee-Yang, W.; Ciblak, M.A.; Benjamin, L.E; Sanza, L.T.; Huie, S.; Yeo, S.F.; Brandt, M.E.; Warnock, D.W. (2004). Incidence of bloodstream infections due to Candida species and in vitro susceptibilities of isolates collected from 1998 to 2000 in a population-based active surveillance program. J. Clin. Microbiol. 42(4); 1519-1527. DOI: 10.1128/JCM.42.4.1519-1527.2004. PMID: 15070998.

24. Lian, C.; Zhao, J.; Zhang, Z.; Liu, W. (2004). Genotype of Candida species associated with different conditions of vulvovaginal candidosis. Mycoses. 47(11-12), 495-502. DOI: 10.1111/j.1439-0507.2004.01049.x. PMID: 15601456.

25. Liu, X.P.; Fan, S.R.; Bai, F.Y.; Li, J.; Liao, Q.P. (2008). Antifungal susceptibility and genotypes of Candida albicans strains from patients with vulvovaginal candidiasis. Mycoses. 52(1), 24-28. DOI: 10.1111/j.1439-0507.2008.01539.x. PMID: 18498300.

26. Lyon, J.P.; Resende, M.A. (2007). Evaluation of adhesion to buccal epithelial cells in Candida species obtained from denture wearers after exposure to fluconazole. Mycoses. 50(1), 21-24. DOI: 10.1111/j.14390507.2006.01292.x. PMID: 17302743.

27. Lockhart, S. R.; Fritch, J.J.; Meier, A.S.; Schroppel, K.; Srikantha, T.; Galask, R.; Soll, D.R. (1995). Colonizing populations of Candida albicans are clonal in origin but undergo microevolution through $\mathrm{C} 1$ fragment reorganization as demonstrated by DNA fingerprinting and C1 sequencing. J. Clin. Microbiol. 33(6), 1501-1509. PMID: 7650175.

28. Lott, T.J.; Holloway, B.P.; Logan, D.A.; Fundyga, R.; Arnold, J. (1999). Towards understanding the evolution of the human commensal yeast
Candida albicans. Microbiology. 145, 1137-1143. DOI: 10.1128/JCM.39.11.4076-4081.2001. PMID: 10376829.

29. Maiden, M.C.J. (2006). Multilocus sequence typing of bacteria. Annu. Rev. Microbiol. $\quad 60, \quad 561-588 . \quad$ DOI: 10.1146/annurev.micro.59.030804.121325. PMID: 16774461.

30. Mata, A. L.; Rosa, R.T.; Rosa, E.A.R.; Goncalves, R.B.; Hofling, J.F. (2000). Clonal variability among oral Candida albicans assessed by allozyme electrophoresis analysis. Oral Microbiol. Immunol. 15(6), 350354. DOI: 10.1034/j.1399-302x.2000.150602.x. PMID: 11154430.

31. Maza, J.L.; Elguezabal, N.; Prado, C.; Ellacuria, J.; Soler, I.; Pontón, J. (2002). Candida albicans adherence to resin-composites restorative dental materials: influence of role human saliva. Oral Surg. Oral Med. Oral Pathol. Oral Radiol. Endod. 94(5), 589-92. DOI: 10.1067/moe.2002.126024. PMID: 12424453.

32. Odds, F.C.; Bougnoux, M.E.; Shaw, D.J.; Bain, J.M.; Davidson, A.D.; Diogo, D.(2007). Molecular phylogenetics of Candida albicans. Eukaryot Cell 6 (6), 1041-1052. DOI: 10.1128/EC.00041-07. PMID: 17416899.

33. Odds, F.C.; Davidson, A.D.; Jacobsen, M.D.; Tavanti, A.; Whyte, J.A.; Kibbler, C.C.; Ellis, D. H.; Maiden, M. C. J.; Shaw, D. J.; Gow N. A. R. (2006). Candida albicans strain maintenance, replacement, and microvariation demonstrated by multilocus sequence typing. J. Clin. Microbiol. 44(10), 3647-3658. DOI: 10.1128/JCM.00934-06. PMID: 17021093.

34. Odds, F.C.; Jacobsen, M.D. (2008). Multilocus sequence typing of pathogenic Candida species. Eukaryot. Cell. 7(7), 1075-1084. DOI: 10.1128/EC.00062-08. PMID: 18456859.

35. Oh, S.H.; Cheng, G.; Nuessen, J.A.; Jajko, R.; Yeater, K.M.; Zhao, X.M.; Pujol, C.; Soll, D.R.; Hoyer, L.L. (2005). Functional specificity of Candida albicans Als3p proteins and clade specificity of ALS3 alleles discriminated by the number of copies of the tandem repeat sequence in the central domain. Microbiol. 151(Pt3), 673-681. DOI: DOI 10.1099/mic.0.27680-0. PMID: 15758214.

36. Pinto, P.M.; Resende, M.A.; Koga-Ito, C.Y.; Tendler, M. (2004). Genetic variability analysis among clinical Candida spp. isolates using random amplified polymorphic DNA. Mem. Inst. Oswaldo Cruz. 99 (2), 147-152. DOI: 10.1590/S0074-02762004000200006. PMID: 15250467.

37. Poulter, R.T. (1987). Natural auxotrophic heterozygosity in Candida albicans. Crit. Rev. Microbiol. 1987. 15:(1), 97-101. DOI: 10.3109/10408418709104452. PMID: 3319426.

38. Pujol, C.; Joly, S.; Lockhart, S.R.; Noel, S.; Tibayrene, M.; Soll, D.R. (1997). Parity among the randomly amplfied polymorphic DNA method, multilocus enzyme electrophoresis, and southern blot hybridization with the moderately repetitive DNA probe $\mathrm{Ca} 3$ for fingerprinting Candida albicans. J. Clin. Microbiol. 35(9), 2348-2358. PMID: 9276415.

39. Pujol, C.; Joly, S.; Nolan, B.; Srikantha, T.; Soll, D.R. (1999). Microevolutionary changes in Candida albicans identified by the complex $\mathrm{Ca} 3$ fingerprinting probe involve insertions and deletions of the 
full-length repetitive sequence RPS at specific genomic sites. Microbiology. 145(Pt10), 2635-2646. PMID: 10537185.

40. Pujol, C.; Pfaller, M.; Soll, D.R. (2002). Ca3 fingerprinting of $C$. albicans bloodstream isolates from the United States, Canada, South America and Europe reveals a European clade. J. Clin. Microbiol. 40(8): 2729-2740. DOI: 10.1128/JCM.40.8.2729-2740.2002. PMID: 12149321.

41. Pujol, C.; Pffaler, M.A.; Soll, D.R. (2004). Flucytosine Resistance Is Restricted to a Single Genetic Clade of Candida albicans. Antimicrob. Agents. Chemother. 48(1), 262-266. DOI: 10.1128/AAC.48.1.262266.2004. PMID: 14693548.

42. Pujol, C.; Reynes, J.; Renaud, F.; Raymond, M.; Tibayrenc, M.; Ayala, F.J.; Janbon, F.; Mallié, M.; Bastide, J.M. (1993). The yeast Candida albicans has a clonal mode of reproduction in a population of infected human immunodeficiency virus-positive patients. Proc. Natl. Acad. Sci. USA. 90(20), 9456-9459. PMID: 8415722.

43. Rho, J.; Shin, J.H.; Song, J.W.; Park, M.R.; Kee, S.J.; Jang, S.J.; Cho, D.; Kee, S.J.; Shin, M.G.; Suh, S.P.; Ryang, D.W. (2004). Molecular investigation of two consecutive nosocomial clusters of Candida tropicalis candiduria using pulsed-field gel electrophoresis. J. Microbiol. 42(2), 80-86. PMID: 15357299.

44. Robles, J.C.; Koreen, L., Park, S.; Perlin, D.S. (2004). Multilocus sequence typing is a reliable alternative method to DNA fingerprinting for discriminating among strains of Candida albicans. J. Clin. Microbiol. 42(6), 2480-2488. DOI: 10.1128/JCM.42.6.2480-2488.2004. PMID: 15184424

45. Rosa, E.A.; Pereira, C.V.; Rosa, R.T.; Höfling, J.F. (2000). Grouping oral Candida species by multilocus enzyme electrophoresis. Int. J. Syst. Evol. Microbiol. 50(Pt3), 1343-1349. PMID: 10843081.

46. Sampaio, P.; Gusmao, L.; Alves, C.; Pina-Vaz, C.; Amorim, A.; Pais, C. (2003). Highly polymorphic microsatellite for identification of Candida albicans strains. J. Clin. Microbiol. 41(2), 552-7. DOI: 10.1128/JCM.41.2.552-557.2003. PMID: 12574245.

47. Schröppel, K.; Rotman, M.; Galask, R.; Mac, K.; Soll, D.R. (1994). Evolution and replacement of Candida albicans strains during recurrent vaginitis demonstrated by DNA fingerprinting. J. Clin. Microbiol. 32(11), 2646-2654. PMID: 7852550.

48. Selmecki, A.; Forche, A.; Berman, J. (2006). Aneuploidy and isochromosome formation in drug-resistant Candida albicans. Science. 313(5785), 367-370. DOI: 10.1126/science.1128242. PMID: 16857942.

49. Schmid, J.; Herd, S.; Hunter, P.R.; Cannon, R.D.; Yasin, M.S.N.; Samad, S.; (1999). Evidence for a general purpose genotype in Candida albicans, highly prevalent in multiple geographic regions, patient types and types of infection. Microbiology 145(Pt9), 2405-2414. PMID: 10517593.

50. Schmid, J.; Hunter, P.R.; White, G.C.; Nand, A.K.; Cannon, R.D. (1995). Physiological Traits Associated with Success of Candida albicans
Strains as Commensal Colonizers and Pathogens. J. Clin. Microbiol. 33(11): 2920-2926. PMID: 8576346.

51. Schmid, J.; Rotman, M.; Reed, B.; Pierson, C.L.; Soll, D.R. (1993). Genetic similarity of Candida albicans strains from vaginitis patients and their partners. J. Clin. Microbiol. 31(1), 39-46. PMID: 8417030.

52. Shin, J.H.; Park, M.R.; Song, J.W.; Shin, D.H.; Jung, S.I.; Cho, D.; Kee, S.J.; Shin, M.G.; Suh, S.P.; Ryang D.W. (2004). Microevolution of Candida albicans strains during catheter-related candidemia. J. Clin. Microbiol. 42(9), 4025-4031. DOI: 10.1128/JCM.42.9.4025-4031.2004. PMID: 15364985.

53. Schulz, W.A. (2005). Molecular Biology of Human Cancers. An Advanced Student's Textbook. Springer Inc., Dordrecht, The Neederlands.

54. Soll DR. (2000). The Ins and Outs of DNA Fingerprinting the Infectious Fungi. Clin. Microbiol. Rev. 13(2): 332-370. PMID: 10756003.

55. Soll, D.R.; Pujol, C. (2003). Candida albicans clades. FEMS Immunol. Med. Microbiol. 39(1), 1-7. DOI: 10.1016/S0928-8244(03)00242-6. PMID: 14556989.

56. Tavanti, A.; Davidson, A.D.; Fordyce, M.J.; Gow, N.A.; Maiden, M.C; Odds, F.C. (2005). Population structure and properties of Candida albicans, as determined by multilocus sequence typing. J. Clin. Microbiol. 43(11), 5601-5613. DOI: 10.1128/JCM.43.11.56015613.2005. PMID: 16272493.

57. Tavanti, A.; Gow, N.A.R.; Maiden, M.C.J.; Odds, F.C.; Shaw, D.J. (2004). Genetic evidence for recombination in Candida albicans based on haplotype analysis. Fungal Genet. Biol. 41(5), 553 2004. DOI: 10.1016/j.fgb.2003.12.008. PMID: 15050544.

58. Tavanti, A.; Gow, N.A.; Senesi, S.; Maiden, M.C.; Odds, F.C. (2003). Optimization and validation of multilocus sequence typing for Candida albicans. J. Clin. Microbiol. 41(8), 3765-3776. DOI: 10.1128/JCM.41.8.3765-3776.2003. PMID: 12904388

59. Wu, W.; Pujol, C.; Lockhart, S.R.; Soll, D.R. (2005). Chromosome loss followed by duplication is the major mechanism of spontaneous matingtype locus homozygosis in Candida albicans. Genetics. 169(3), 13111327. DOI: 10.1534/genetics.104.033167. PMID: 15654090.

60. Zhao, X.; Oh, S.H.; Cheng, G.; Green, C.B.; Nuessen, J.A.; Yeater, K.M.; Leng, L.P.; Brown, A.J.P.; Hoyer, L.L. (2004) ALS3 and ALS8 represent a single locus that encodes a Candida albicans adhesin; functional comparisons between Als3p and Als1p. Microbiology. 150(Pt7): 2415-2428. DOI: 10.1099/mic.0.26943-0. PMID: 15256583.

61. Zhao, X.; Oh, S.H.; Jajko, R.; Diekema, D.J.; Pfaller, M.A.; Pujol, C.; Soll, D.R.; Hoyer, L.L. (2007). Analysis of ALS5 and ALS6 allelic variability in a geographically diverse collection of Candida albicans isolates. Fungal Genet. Biol. 44(12), 1298-1309. DOI: 10.1016/j.fgb.2007.05.004. PMID: 17625934. 